\title{
How Low Can You Go? Low Pressure Drop Laboratory Design
}

\author{
John Weale, P.E. and Peter Rumsey, P.E. \\ Rumsey Engineers \\ 99 Linden Street \\ Oakland, California 94607 \\ Dale Sartor, P.E. \\ Applications Team \\ Building Technologies Department \\ Environmental Energy Technologies Division \\ Ernest Orlando Lawrence Berkeley National Laboratory \\ University of California \\ 1 Cyclotron Road \\ Berkeley, California 94720-8134 \\ Lee Eng Lock \\ Electric Eye Pte Ltd \\ 26 Ayer Rajah Crescent \#05-01 \\ Singapore 139944
}

December 1, 2001

\section{Table of Contents}

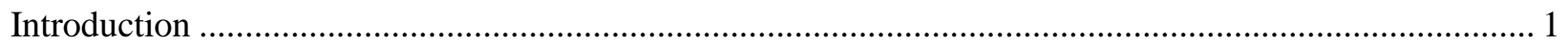

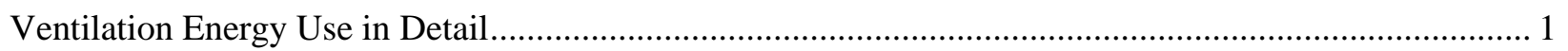

Air Handlers_-Low Face Velocity Design Benefits .................................................................. 3

Heat Recovery Device Selection —Pressure Drop Impacts .................................................................... 5

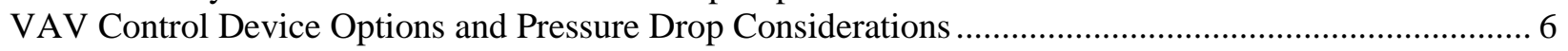

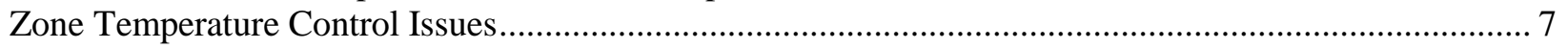

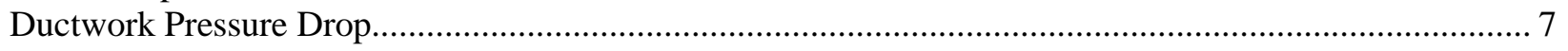

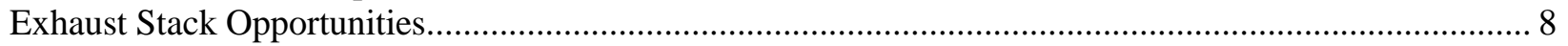

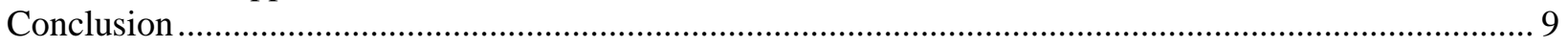

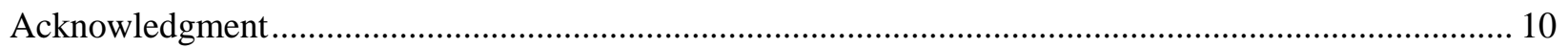

This work was supported by the U.S. Environmental Protection Agency and by the Assistant Secretary for Energy Efficiency and Renewable Energy, Office of Building Technology, State and Community Programs, Office of Building Research and Standards of the U.S. Department of Energy under Contract No. DE-AC03-76SF00098. 


\section{How Low Can You Go? Low Pressure Drop Laboratory Design}

\section{Introduction}

Laboratory buildings are characterized by the production of potentially hazardous fumes within the occupied space. The primary objective of a laboratory ventilation system is to isolate and protect the occupants from the fumes, as well as provide minimum outside air at a comfortable temperature. Fume removal results in the need for a large volume of conditioned make-up air, typically a significantly greater volume than required for space temperature conditioning purposes. The high quantity of exhaust naturally results in a once through system, which is also often required by codes that prohibit any recirculation in a laboratory space. The high costs associated with high airflow systems are magnified by the 24 hours a day, 356 days a year ventilation operation often seen in laboratory situations. All too often, the common design approach taken to laboratory mechanical systems results in a traditional office ventilation system upsized to meet a laboratory's requirements.

Recognizing the unique aspects of laboratory requirements and operation is essential to optimizing the mechanical system. Figure 1 shows a breakdown of a laboratory building's electricity use, based on a DOE 2 model of a baseline laboratory building design for Montana State University (Bozeman, MT).

In laboratory buildings, the largest and easiest target for energy use reduction is usually the ventilation energy. At about $50 \%$ of the buildings total electricity usage, a $15 \%$ reduction in the power required by the ventilation system would save more energy than eliminating all lighting energy. As the largest component of a laboratory's energy consumption, the ventilation system is the first target to reduce the energy bill. Significantly improving the standard design efficiency of a ventilation system requires a lower air pressure drop system on both the supply and exhaust system.

Implementing low-pressure drop design strategies from the early stages of the design process will result in much lower energy costs throughout the system's life with a minimal increase in first costs. The pressure drop in a laboratory ventilation system is influenced by many independent design challenges. Knowing what these design challenges are and how they can be answered to minimize pressure drop is critical in achieving an energy efficient laboratory.

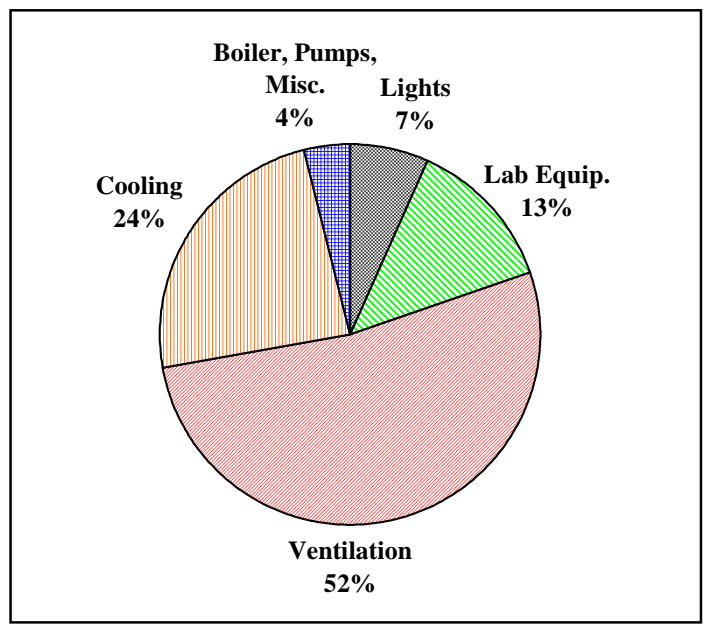

Figure 1. Typical lab electrical use by category. 


\section{Ventilation Energy Use in Detail}

The electrical power requirements of the ventilation system represents the combined supply and exhaust fan power. Heating is provided by natural gas and is not represented in this graph. This fan power can be estimated by the following equation:

Airflow in CFM $\times$ System air pressure drop, in inches w.g 6345 , constants factor $\times$ Fan system efficiency, $\eta_{\text {fan }} \times \eta_{\text {motor }} \times \eta_{\text {drive }}$

Reducing the energy consumed by a laboratory's ventilation system requires changing one or more of the three variables in the equation above: Fan System Efficiency, Airflow, or System Pressure Drop. Table 1 offers a relative guide to the areas of opportunity to reduce the power requirement of a laboratory ventilation system.

Table 1. Ventilation Energy Saving Potential

\begin{tabular}{|l|c|l|}
\hline \multicolumn{1}{|c|}{ Parameter } & \multicolumn{1}{|c|}{$\begin{array}{c}\text { Typical Potential for } \\
\text { Ventilation Energy Savings } \\
\text { Versus Traditional Design }\end{array}$} & \multicolumn{1}{c|}{ Comment } \\
\hline Fan System Efficiency & $5 \%-15 \%$ & $\begin{array}{l}\text { Minor potential, traditional } \\
\text { design often does okay. }\end{array}$ \\
\hline Airflow & $0 \%-60 \%$ & $\begin{array}{l}\text { VAV supply and exhaust systems } \\
\text { offer big fan and conditioning } \\
\text { energy savings over constant } \\
\text { flow; dependent on facility usage } \\
\text { (diversity) }\end{array}$ \\
\hline System Pressure Drop & $30 \%-65 \%$ & $\begin{array}{l}\text { Traditional design results in poor } \\
\text { laboratory systems; large } \\
\text { reductions are possible in } \\
\text { numerous areas. }\end{array}$ \\
\hline
\end{tabular}

Standard design practice usually results in a fan system efficiency of around 62\%. Careful selection of a direct drive fan and use of high efficiency motors can push that efficiency up to around $72 \%$, at best resulting in a power reduction of about $15 \%$. While an important aspect of design, minimal opportunity is available and, if energy efficiency is emphasized as important design criteria, conventional design methods can optimize the fan efficiency.

The airflow through the system is typically set by the requirements of the facility, with three key design decisions separating typical laboratory facilities from energy efficient ones. The largest design decision is to use a variable flow exhaust system, rather than a constant flow system. Varying the supply and exhaust flows based on actual usage immediately captures the significant savings possible from reducing the flow.

With a variable volume system, diversity in the exhaust load typically results in the majority of system operation at a $25 \%$ or greater reduction in airflow. For the same ductwork size and similar fans, reducing the airflow reduces the fan power by approximately the cube (a simplified fan law relationship). Using the cube relationship, a $25 \%$ reduction of airflow results in about a 58\% reduction in the fan power required. In practice, the fan energy savings are slightly lower, but the fan law suggested savings are a reasonable first estimate of the magnitude of the ventilation energy reduction potential. Additional energy savings are realized by a $25 \%$ reduction in the amount of air that is conditioned. 
The second design decision typically impacting laboratory airflow levels is the determination of the minimum laboratory airflow rate. Standard design frequently results in a high minimum laboratory airflow, which increases both the fan and conditioning energy requirements. A minimum airflow rate exceeding $1 \mathrm{CFM}$ /square foot should be carefully investigated to verify it is truly necessary. For example, if a high airflow is set due to spill concerns, consideration should be given to a monitoring or 'Panic Button' system that allows for a rapid emergency increase in ventilation when required.

The final variable that determines the amount of power consumed by the ventilation system is the one that typically offers the greatest potential for energy savings: the system air pressure drop. Despite the huge impact of the ventilation system on yearly energy consumption, it is not uncommon to see laboratory buildings with a supply and exhaust system combined total of 8-12 in. w.g. pressure drop. As seen from the fan power equation above, this very high pressure drop directly results in a high power consumption ventilation system. To reduce the ventilation energy consumption, all that is required is a reduction in the system's pressure drop. This is the area with the most opportunities to significantly improve the efficiency of a laboratory ventilation system.

The pressure drop in a laboratory ventilation system should be addressed throughout both the supply and exhaust sides of the system.

\section{Air Handlers-Low Face Velocity Design Benefits}

Traditional air handler design for office buildings sets the size of the air handler based on a face velocity of $500 \mathrm{fpm}$. Originally based on balancing the first cost with the lifetime energy cost of equipment, this decades-old rule of thumb face velocity was never intended for sizing a unit that operates 8,760 hour per year, and is now rather questionable even for sizing standard modern office units. The reason the face velocity is so important is it has a direct impact on the energy consumption of the air handler.

By selecting a lower face velocity, the pressure drop of the air handling unit, and the proportional energy consumption, is reduced. As described in Figure 2, a reduction in the face velocity reduces the power requirement by the square of the velocity reduction, for example a $25 \%$ reduction in face velocity yields a $44 \%$ reduction in power requirement. The standard arguments against reducing the face velocity, which usually are refuted by the large energy life-cycle energy costs of a laboratory system situation, are that the first cost is too high and it requires too much floor space or additional ceiling height.

The argument that decreasing the face velocity results in unacceptable cost increases fails on two fronts. The first is that the $500 \mathrm{fpm}$ 'standard' is a carry over from the sub-4000 hour per year operation of a typical office air handler. The lifetime energy consumption costs of a laboratory system, even neglecting the typically much higher pressure drops, are double those of an office air handler. It is not possible for the $500 \mathrm{fpm}$ rule of thumb for minimizing the lifetime costs of office air handlers to apply to both 10 hours a day and 24 hours a day operation, and no substantive argument beyond convenience can be made for its continued use. The second consideration is that a lower face velocity unit not only results in much lower energy consumption, it also tends to add little, if any, first cost when properly designed.

It is easy to understand how lowering the face velocity requires a larger and therefore more expensive enclosure. But any analysis of the added cost should not end with the enclosure cost, since the lowered energy requirements reduces the cost of most other components. The coil will have double the surface area, but half the rows, resulting in a minimal cost increase. The fan motor size in a typical system can be reduced by $25 \%$ to $50 \%$ due to the lower pressure drop in the air handler alone. A smaller fan motor saves money, as does a smaller VFD, smaller wiring, and smaller circuits required to supply the motor. More filters will be required to fill the greater face area, but the filter change interval can be extended a proportional amount, resulting in no additional filter cost on an annual basis. A reduction in maintenance due to longer intervals between filter changes will result in a lower maintenance cost over the life of the 


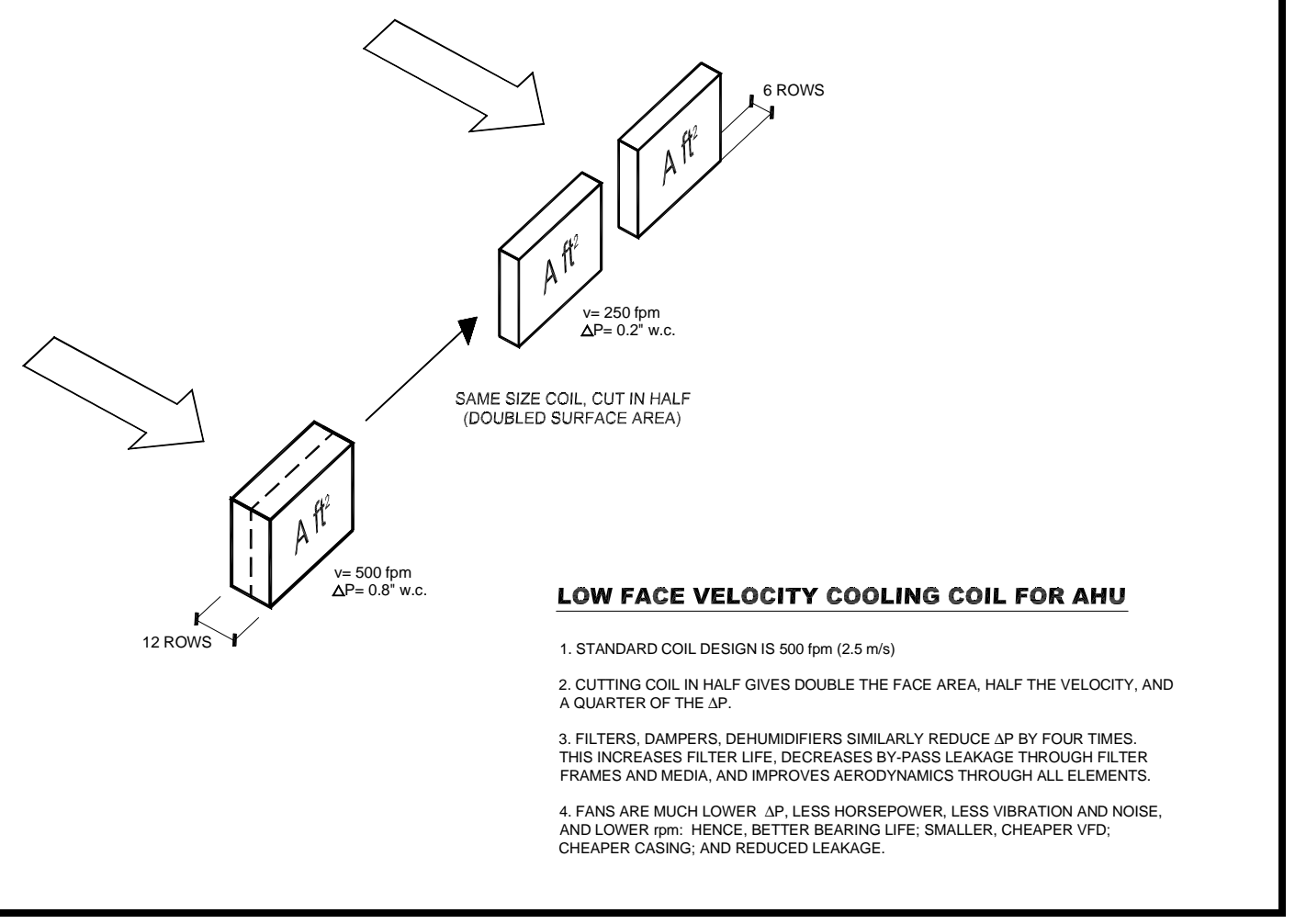

Figure 2. Low face velocity coils.

unit. When all these effects are considered, the real cost increase of an "oversized" low face velocity air handler versus a standard unit is often negligible.

The additional floor space required by a lower face velocity air handler is typically small. When evaluating the options, it is important to keep in mind that the air handler represents a significant amount of the system pressure drop in a very compact package. The air handler, with the internal filtration and coils, represents over $25 \%$ of the total supply and exhaust system pressure drop (about half of the supply system drop). Reducing the face velocity in a typical 20,000 CFM AHU by $25 \%$ increases the width of the unit by only about 2 feet, requiring perhaps an additional 50 square feet of mechanical floor space (assuming that the height can not be increased at all). The impacts of a slightly larger face area air handler on the architectural requirements of the air handler system are negligible when incorporated from the initial design stages. Table 2 illustrates performance targets for standard, good, and better design of air handlers.

Table 2. Air Handler Pressure Drop Performance

\begin{tabular}{llll}
\multicolumn{1}{c}{ Component } & \multicolumn{1}{c}{ Standard } & \multicolumn{1}{c}{ Good } & \multicolumn{1}{c}{ Better } \\
\hline Air handler face velocity & 500 & 400 & 300 \\
Air Handler Pressure Drop & 2.5 in.w.g. & 1.5 in. w.g. & 0.75 in.w.g.
\end{tabular}




\section{Heat Recovery Device Selection-Pressure Drop Impacts}

Due to the once through operation of laboratory ventilation systems, in all but the most moderate climates, a heat recovery system is often an attractive option. A properly operating heat recovery system will preheat the supply air in the winter and precool it in the summer from the exhaust airflow. There are four commonly used heat recovery systems that are usually considered for this type of system: heat recovery wheel, flat plate air-to-air heat recovery device, heat pipes or a run around coil. All of the systems have their own unique pros and cons, but any evaluation of the cost savings from the heat recovery must consider the additional fan costs associated with the pressure drop through the device. Additional design considerations, particularly control methods to avoid icing up in cold climates and concerns about contamination of the supply air with exhaust, are important parts of the design but do not impact the pressure drop and are not addressed here.

The heat recovery wheel functions by exposing a material to the exhaust stream and then moving the material, heated or cooled by the exhaust stream, into the supply stream. The ability to recovery significant amounts of latent heat through the use of desiccant coatings on the wheel can offer better total heat recovery performance than other methods.

A significant design issue with heat wheels is the potential for crossover, or the mixing of a small amount of exhaust air into the supply air stream. Heat recovery wheels are available with a "purge" segment to address these crossover concerns. Any additional fan energy required to supply purge airflow should be considered in the design evaluation process. In some extreme design situations, a purge section may not be considered adequate to isolate the supply from the exhaust pollutants.

For small applications, the heat recovery wheel can easily be sized to offer a reasonably low-pressure drop. In larger applications, the first cost considerations of many low-pressure drop wheel selections can cause concern. The need for protection from crossover typically requires a significant purge section, resulting in a greater total CFM increasing the total fan energy required.

A heat wheel also requires the main supply and exhaust ducts to essentially cross through each other. Laboratory design, with strict requirements on separation of the exhaust and intake locations, makes physically crossing the supply and exhaust ducting difficult. However, with architectural cooperation and careful configuration of the ducting system, it is possible the duct layout requirements can be fulfilled with an efficient, low-pressure drop layout.

The flat plate heat exchanger system is a simple heat recovery option. It offers good effectiveness and can be specified for a low-pressure drop system. There are two key pressure drop issues to address with a flat plate heat exchanger. The first is the design of a low-pressure drop system with a flat plate heat exchanger requires care in the heat-ducting layout. As with the heat wheel, the supply and exhaust ductwork must cross each other. The second issue is simply the specification of the heat exchanger itself. To achieve the best possible performance will require a pressure drop of 0.25 " w.g. on the supply side, and an equal or lower pressure drop on the exhaust side. This will often require the specification of units that are physically very large. An additional considerable specification issue is the necessity of addressing any corrosion concerns with appropriate plate coatings or material selection.

A heat pipe system offers excellent heat recovery performance. Utilizing refrigerant and a material (often sintered metal) with a strong wicking action, a large amount of heat can be recovered from an exhaust stream. One problem with heat pipes is a restriction on the supply and exhaust duct layout even more stringent than that imposed by a flat plate heat exchanger. The additional restrictions on the ducting layout increase the design challenge of laying out a clean, low-pressure drop ducting system. Heat pipes not only require the supply and exhaust streams be brought adjacent to one another, they also require a specific vertical/horizontal arrangement, since heat pipes are gravity sensitive devices. At this time, heat 
pipes are also a more expensive technology, which results in a tendency to size them for a high pressure drop, 1.0 in. w.g. or higher, in an effort to minimize first cost.

Run around coil systems have been in use for a long time for energy recovery in a variety of situations. A coil is added to both the supply and return exhaust streams and a small pump is used to circulate fluid between the two coils, recovering heat from one stream and delivering it to the other. From a design standpoint, runaround coils can require significant effort to properly specify and optimize, but offer great flexibility to minimize pressure drop. When combined with a low face velocity air handler, a run around coil system can offer good heat recovery performance and very low pressure drop.

A heat recovery system was analyzed in some detail for the recent EPICenter laboratory building designed for Montana State University. With a design exhaust quantity of 44,000 CFM and a design outside air temperature of $-20^{\circ} \mathrm{F}$, heat recovery was a very important part of the design. Using hourly weather data, the annual savings from a flat plate heat exchanger were compared to a run around coil.

After accounting for the relative fan energy and pumping energy costs, the glycol based run around coil offered slightly better energy savings, despite having a lower peak heat recovery effectiveness. The run around coil offered a peak effectiveness of about $60 \%$, compared to a flat plate system with a peak effectiveness of $80 \%$. The differences in efficiency could not overcome the fan energy cost associated with the flat plate system in this case. The mechanical space available in this particular job simply did not allow a low-pressure drop implementation of a flat plate system, which requires the crossing of the supply and exhaust ductwork. Table 3 compares pressure drop performance targets for standard, good, and better heat recovery designs.

Table 3. Heat Recovery Pressure Drop

\begin{tabular}{llll}
\multicolumn{1}{c}{ Component } & Standard & Good & Better \\
\hline $\begin{array}{l}\text { Heat Recovery Device Pressure } \\
\text { Drop (per airstream) }\end{array}$ & $\begin{array}{l}1.00 \text { in. w.g. } \\
\text { (when present) }\end{array}$ & 0.60 in. w.g. & 0.35 in. w.g.
\end{tabular}

\section{VAV Control Device Options and Pressure Drop Considerations}

As discussed in the introduction, a variable flow supply and exhaust system reduces the airflow, the power required is reduced by approximately the cube of the flow reduction. Reducing the quantity of exhaust when hoods are not in use reduces the fan power, heating cost and cooling cost. Quite often laboratory design assumes a usage factor of 1, or that all hoods will be operating simultaneously. This results in the supply and exhaust volumes being oversized for the majority of the operating hours, making laboratories prime candidates for variable flow systems capable of following the actual load.

The largest challenge in applying variable flow systems in laboratories is ensuring the balance between supply and exhaust is maintained properly. The exhaust hoods should not be starved for make-up air, but the laboratory needs to be slightly under supplied with air to maintain a negative pressure relative to adjacent spaces (NFPA Standard 45). There are numerous systems offered for maintaining the precise airflow control required for effective variable exhaust systems utilizing two general methods: direct measurement of the air flows or measurement of pressure differences (or flow through a small orifice between the spaces of interest-inside the hood to the lab, or from the lab to an adjacent space).

While the methods are radically different, the end results are comparable. Both techniques have been demonstrated to provide safe and efficient laboratory systems. The primary difference of note with regards to system pressure drop is that the pressure drop associated with pressure independent flow 
measurement valves is about $0.60-0.30$ in. w.g. versus about 0.05 in. w.g. pressure drop across a typical butterfly control damper. See Table 4 for a comparison of design pressure drop through control devices. The $0.25 \mathrm{in} \mathrm{w.g.} \mathrm{pressure} \mathrm{difference} \mathrm{on} \mathrm{the} \mathrm{supply} \mathrm{and} \mathrm{exhaust} \mathrm{side} \mathrm{equates} \mathrm{to} \mathrm{roughly} 580 \mathrm{kWh}$ per year per 6' hood. Over an entire lab facility, the extra energy usage for that single component adds up quickly.

Table 4. Control Device Pressure Drop

\begin{tabular}{llll}
\multicolumn{1}{c}{ Component } & \multicolumn{1}{c}{ Standard } & \multicolumn{1}{c}{ Good } & Better \\
\hline VAV Control & Constant Volume, NA & $\begin{array}{l}0.30-0.60 \text { in. w.g. } \\
\text { per device }\end{array}$ & 0.10 in. w.g. \\
$\begin{array}{l}\text { Devices Pressure } \\
\text { Drop }\end{array}$ & & & \\
\hline
\end{tabular}

1) No standard judgment is passed on the relative control merits of the flow control methods, just on the relative pressure drops (and associated efficiency potential). Other design requirements can affect the best choice selection.

\section{Zone Temperature Control Issues}

The typical method to provide zone temperature control is to provide a zone reheat coil and a cooling coil. The disadvantage of this configuration is the pressure drop incurred by the zone coil(s) 8,760 hours a year.

Several ways exist to minimize the air pressure drop cost of zone coils. A good approach is to lower the coils' pressure drop, for the same general reasons as discussed for air handlers. The better approach is to remove the zone coils from the primary supply. Several design options allow this, including radiant floors and ceilings, baseboard radiators, fan coils in the space and/or providing a low-pressure drop coil bypass.

There are a number of design issues to watch when implementing these strategies. The controls system and algorithms, including supply air temperature reset and variable speed fan control, are important aspects of efficient operation. For example, if the supply air temperature is not reset, the reheat load may exceed the capacity of a radiant system during low load periods. Another example would be a zone coil bypass that would have no savings if the supply fan is controlled to a constant static setpoint, causing the zone flow control damper to add back the pressure drop of the bypassed zone coil. See Table 5 for a comparison of standard, good, and better design of zone coil pressure drop.

Table 5. Zone Coil Pressure Drop

\begin{tabular}{cccc} 
Component & Standard & Good & Better \\
\hline Zone Coil Pressure Drop & 0.5 in. w.g. & 0.30 in. w.g. & 0.05 in. w.g.
\end{tabular}

\section{Ductwork Pressure Drop}

One simple measure to reduce the ductwork pressure drop, and cost, is to manifold fume hoods. Combined with a variable air volume fume hood system, connecting all the hoods to a common exhaust duct allows for significant energy savings by taking advantage of diversity. Manifolding exhaust is also essentially a prerequisite for both a heat recovery system and the most efficient exhaust fan and stack options. A manifold system is also typically cheaper to construct and maintain than a configuration with a separate fan for every hood.

Reducing the ductwork pressure drop is perhaps the easiest design change that can be made to improve the efficiency of a laboratory's mechanical system, since it requires little change to the traditional 
methods of design. As with the air handler, supply ductwork is usually designed to a rule of thumb target pressure drop using the constant pressure drop method carried over from office conditioning design.

A common pressure drop range used for duct sizing in office buildings is $0.1 \mathrm{in}$. w.g. per $100 \mathrm{ft}$. of duct, sometimes higher. In a laboratory building, with 8,760 operation, it is often reasonable to design to half this pressure drop. Decreasing this design parameter to $0.05 \mathrm{in}$. w.g. per $100 \mathrm{ft}$. is a simple step to decrease the ducting pressure drop and is defensible as halving the ventilation energy consumption attributable to the ducting system without doubling the installation cost.

Exhaust ductwork is often sized using a different technique, the constant velocity method. This method is not appropriate for variable flow systems, and can lead to higher pressure drop systems. It should only be used in the few cases where it is required. A constant velocity design is only required when particulates will be present in the exhaust. The typical laboratory has high volumes of fume and vapor exhaust that do not require or benefit from a constant velocity system. In the rare cases where particulate exhaust is required, a separate, small exhaust system should be used to avoid incurring the energy penalty of high pressure drop constant velocity design on the high volumes of fume exhaust.

The incremental cost of larger ductwork is often over emphasized. Lower pressure drop design can reduce the complexity of ductwork, using fewer contraction fittings and shorter, more direct, layout (usually requiring the cooperation of the project architect). The labor and fitting costs associated with numerous duct contractions versus longer runs of a single larger diameter duct help offset the additional material cost. There are also construction management efficiencies to be gained from having fewer sizes of ductwork used in a project, for example if only 24" and 18" diameter round ductwork and fittings are used for the distribution ducting. See Table 6 for a comparison of target ductwork pressure drops.

Table 6. Ductwork Pressure Drop

\begin{tabular}{cccc}
\cline { 2 - 3 } Component & Standard & Good & Better \\
\hline $\begin{array}{l}\text { Ductwork Pressure Drop } \\
\text { (supply/exhaust) }\end{array}$ & $2.0 / 2.0$ in. w.g. & $1.0 / 1.5$ in. w.g. & $0.5 / 0.6$ in. w.g.
\end{tabular}

\section{Exhaust Stack Opportunities}

Laboratory exhaust requires a stack or some other measure (dilution, high velocity discharge, etc.) to eliminate recirculation of potentially toxic contaminants. To ensure adequate dilution of the exhaust before it enters an occupied space, it must be ejected from either a significant height or at a high velocity (around 4,000 fpm). Even when a tall stack is used, a high exit velocity of 2000-3000 fpm is recommended (ASHRAE, AIHA). The fan energy required to supply this velocity, which is part of the total pressure drop as velocity pressure, and the pressure drop in the stack itself are the most significant components of the exhaust system pressure drop. In a constant volume system, the stack pressure drop can be minimized using conventional duct design techniques. Minimizing the pressure drop in a variable exhaust system is made more difficult since the exhaust flow is varying, but a constant exit velocity is required.

One approach to a variable flow exhaust system is to maintain a constant volume through the stack itself by drawing in dilution air immediately prior to the exhaust fan. The dilution air allows for safe operation of the stack even when the laboratory exhaust volume has dropped to the point where the stack exit velocity would be too low to ensure proper dispersion. Dilution air incurs a fan power penalty since more airflow than is required by the laboratory process is being pushed by the exhaust fan through and out the stack, typically at a pressure drop in excess of $0.55 \mathrm{in} \mathrm{w.g.} \mathrm{when} \mathrm{the} \mathrm{velocity} \mathrm{pressure} \mathrm{is} \mathrm{factored} \mathrm{in.} \mathrm{This}$ 
fan power penalty is still far superior to a constant volume system where at low exhaust load conditions the dilution air is essentially drawn from the conditioned laboratory space.

An alternative method is to have multiple fans, each with a dedicated stack, drawing from a common exhaust plenum. As the required exhaust volume drops, fans and their dedicated stacks are staged off. Motorized or flow actuated backflow dampers are utilized to minimize leakage through shut-off stacks back into the plenum. Reducing the number of stacks in use allows for a safe exit velocity to be maintained without maintaining a constant high volume flow through the exhaust system.

A staged exhaust stack approach was used in a retrofit performed at the U.S. Department of Agriculture Salinity Laboratory in Riverside, California where fume hoods were converted in groups of four from individual dedicated fans and exhausts to a common manifold. The pre-existing exhaust fans, one for each of the four hoods per manifold, were staged as required to serve the common plenum. The fan staging varies both the airflow and the total operating exhaust stack outlet area as the exhaust flow varies with hood usage. A simple pneumatic damper is used to close off stacks that are not in use, while the fan location keeps the common plenum under negative pressure ensuring that any leakage past the stack shutoff damper is into the plenum rather than fumes leaking out. See Table 7 for a comparison of target exhaust stack pressure drops for standard, good, and better design.

\section{Table 7. Exhaust Stack Pressure Drop}

\begin{tabular}{clll} 
Component & \multicolumn{1}{c}{ Standard } & \multicolumn{1}{c}{ Good } & \multicolumn{1}{c}{ Better } \\
\hline Exhaust Stack & 0.7"w.g. full design & 0.7"w.g. full & 0.75" w.g. averaging \\
& flow through entire & design flow through & half the design flow, \\
& exhaust system, & fan and stack only, & VAV System with \\
& Constant Volume & $\begin{array}{l}\text { VAV System with } \\
\text { bypass }\end{array}$ & multiple stacks \\
& &
\end{tabular}

\section{Conclusion}

Table 8 sums up the impact that Good and Better design practices can have on the design of a laboratory ventilation system. The ventilation system is a large consumer of energy in a laboratory building, and should be recognized and designed as such. The values in the table below offer some guideline values for evaluating the air pressure drop of a ventilation design. Pressure drop is frequently neglected in ventilation design, to the detriment of economical facility operation.

The fan power equation, given earlier in the discussion on Ventilation Energy Use in Detail, can be used with some basic assumptions to convert the values in Table 8 into the commonly used metric of Watts/CFM.

Assume:

0.62 Fan system efficiency (70\% efficient fan, $90 \%$ efficient motor, $98 \%$ efficient drive)

8.51 constants factor (for results in Watts rather than horsepower)

Then:

9.7 in w.g. total pressure drop equals $1.8 \mathrm{~W} / \mathrm{CFM}$

6.2 in w.g. total pressure drop equals $1.2 \mathrm{~W} / \mathrm{CFM}$

3.2 in w.g. total pressure drop equals $0.6 \mathrm{~W} / \mathrm{CFM}$

In laboratory buildings, the pressure drop of the ventilation system is directly responsible for the majority of a laboratory facility's energy usage. By making pressure drop a priority in the design of the ventilation 
system and using good design practice, significant pressure drop reductions can be achieved over standard design. Lower pressure drop systems directly contribute to more efficient and more economical laboratories, with the potential for over $25 \%$ reductions in overall building electricity use. These efficient design techniques can be implemented with no compromises or limitations on the facility operation, offering good energy savings through good design.

Table 8. Summary of Laboratory Air Flow Pressure Drop

\begin{tabular}{|c|c|c|c|}
\hline Component & Standard & Good & Better \\
\hline Air handler face velocity & 500 & 400 & 300 \\
\hline Air Handler Pressure Drop & 2.5 in. w.g. & 1.5 in. w.g. & 0.75 in.w.g. \\
\hline $\begin{array}{l}\text { Heat Recovery Device } \\
\text { Pressure Drop }\end{array}$ & 1.00 in. w.g. & 0.60 in. w.g. & 0.35 in. w.g. \\
\hline $\begin{array}{l}\text { VAV Control Device } \\
\text { Pressure Drop }\end{array}$ & $\begin{array}{l}\text { Constant Volume, } \\
\text { N/A }\end{array}$ & $\begin{array}{l}\text { Flow Measurement } \\
\text { Devices, } 0.60-0.30 \\
\text { in. w.g. }\end{array}$ & $\begin{array}{l}\text { Pressure Differential } \\
\text { Measurement and } \\
\text { Control, } 0.10 \text { in. w.g. }\end{array}$ \\
\hline $\begin{array}{l}\text { Zone Temperature Control } \\
\text { Coils Pressure Drop }\end{array}$ & 0.5 in. w.g. & 0.30 in. w.g. & 0.05 in. w.g. \\
\hline $\begin{array}{l}\text { Total Supply and Return } \\
\text { Ductwork Pressure Drop }\end{array}$ & 4.0 in. w.g. & 2.25 in. w.g. & 1.2 in. w.g. \\
\hline $\begin{array}{l}\text { Exhaust Stack Pressure } \\
\text { Drop }\end{array}$ & $\begin{array}{l}0.7 \text { " w.g. full design } \\
\text { flow through entire } \\
\text { exhaust system, } \\
\text { Constant Volume }\end{array}$ & $\begin{array}{l}0.7 \text { " w.g. full design } \\
\text { flow through fan and } \\
\text { stack only, VAV } \\
\text { System with bypass }\end{array}$ & $\begin{array}{l}0.75 \text { " w.g. averaging } \\
\text { half the design flow, } \\
\text { VAV System with } \\
\text { multiple stacks }\end{array}$ \\
\hline $\begin{array}{l}\text { Noise Control (Silencers) } \\
\text { Pressure Drop }\end{array}$ & $1.0 " \mathrm{w} . \mathrm{g}$. & $0.25 "$ w.g. & $0.0 "$ w.g. \\
\hline Total & 9.7" w.g. & $6.2 " \mathrm{w} . \mathrm{g}$. & $3.2 " \mathrm{w} . \mathrm{g}$. \\
\hline Approximate W/CFM & 1.8 & 1.2 & 0.6 \\
\hline
\end{tabular}

\section{Acknowledgment}

This work was supported by the U.S. Environmental Protection Agency and by the Assistant Secretary for Energy Efficiency and Renewable Energy, Office of Building Technology, State and Community Programs, Office of Building Research and Standards of the U.S. Department of Energy under Contract No. DE-AC03-76SF00098. 